\title{
Formation of Amorphous Oxide Layer on the Crystalline Al-Ni-Y Alloy
}

\author{
Kang Cheol Kim, Won Tae Kim¹, Do Hyang Kim* \\ Center for Non-crystalline Materials, Department of Materials Science and Engineering, Yonsei University, Seoul 120-749, Korea \\ ${ }^{1}$ Department of Optical Engineering, Cheongju University, Cheongju 360-764, Korea
}

*Correspondence to:

$\mathrm{Kim} \mathrm{DH}$,

Tel: +82-2-2123-4255

Fax: +82-2-312-8281

E-mail: dohkim@yonsei.ac.kr

Received December 17, 2013

Revised December 23, 2013

Accepted December 23, 2013
The oxidation behavior of the crystallized $\mathrm{Al}_{87} \mathrm{Ni}_{3} \mathrm{Y}_{10}$ alloy has been investigated with an aim to compare with that of the amorphous $\mathrm{Al}_{87} \mathrm{Ni}_{3} \mathrm{Y}_{10}$ alloy. The oxidation at $873 \mathrm{~K}$ occurs as follows: (1) growth of an amorphous aluminum-yttrium oxide layer $(\sim 10 \mathrm{~nm})$ after heating up to $873 \mathrm{~K}$; and (2) formation of $\mathrm{YAlO}_{3}$ crystalline oxide $(\sim 220 \mathrm{~nm})$ after annealing for 30 hours at $873 \mathrm{~K}$. Such an overall oxidation step indicates that the oxidation behavior in the crystallized $\mathrm{Al}_{87} \mathrm{Ni}_{3} \mathrm{Y}_{10}$ alloy occurs in the same way as in the amorphous $\mathrm{Al}_{87} \mathrm{Ni}_{3} \mathrm{Y}_{10}$ alloy. The simultaneous presence of aluminum and yttrium in the oxide layer significantly enhances the thermal stability of the amorphous structure in the oxide phase. Since the structure of aluminum-yttrium oxide is dense due to the large difference in ionic radius between aluminum and yttrium ions, the diffusion of oxygen ion through the amorphous oxide layer is limited thus stabilizing the amorphous structure of the oxide phase.

Key Words: Metallic glass, Oxidation, Amorphous oxide

\section{INTRODUCTION}

Recently, metallic glasses receive a great attention since they have some exotic properties which cannot be obtained in the counterpart crystalline alloys (Han et al., 2011). Using the property of highly viscous flow in the supercooled liquid region (SLR), metallic glasses can be fabricated in various $\mathrm{nm}$ or $\mu \mathrm{m}$ scale forms such as such as nano-wires or nanopatterns (Carmo et al., 2011; Nakayama et al., 2012). Another important property of the SLR is that it can be used as a wetting agent, for example, for consolidation of metallic powders. Therefore, metallic glasses can be utilized for various functional purposes, for example, electrode formation in electronic devices. To take advantage of such superior characteristics of metallic glass, however, it is strongly required that metallic glasses should have a good oxidation resistance. It has been reported that the oxidation tendency of the metallic glasses is dependent on the alloy systems and compositions. Recent study on the oxidation behavior in $\mathrm{Cu}-$ $\mathrm{Zr}$ based metallic glass shows that $\mathrm{Cu}-\mathrm{Zr}-\mathrm{Al}$ metallic glass has inferior oxidation resistance to $\mathrm{Cu}-\mathrm{Zr}$ binary metallic glass (Lim et al., 2012), but Cu-Zr-Al-Be metallic glass has far better oxidation resistance (Lim et al., 2013a). The important criterion for the enhancement of the oxidation resistance is the formation of an amorphous oxide (instead of the crystalline oxide layer) and its thermal stability (Lim et al., 2013b).

Since the cell efficiency of the Si solar cell is much more enhanced when Al-based metallic glass is used as wetting agent of Ag powders (Kim et al., 2012), detailed study on the high temperature oxidation behavior of the Al-Ni-Y metallic glass has been performed (Kim et al., 2013). When $\mathrm{Al}_{87} \mathrm{Ni}_{3} \mathrm{Y}_{10}$ ternary metallic glass is oxidized at $873 \mathrm{~K}$, the overall oxidation process can be described as follows: (1) formation of a native amorphous oxide layer ( $\sim \mathrm{nm})$; (2) growth of an amorphous aluminum-yttrium oxide layer $(\sim 12 \mathrm{~nm})$ after heating up

This work was supported by the Global Research Laboratory Program of the Korean Ministry of Education, Science and Technology.

@ This is an open-access article distributed under the terms of the Creative Commons Attribution Non-Commercial License (http://creativecommons.org/licenses/by-nc/3.0) which permits unrestricted noncommercial use, distribution, and reproduction in any medium, provided the original work is properly cited.

Copyrights @ 2013 by Korean Society of Microscopy 
to $873 \mathrm{~K}$; (3) growth of an amorphous oxide layer (100 130 $\mathrm{nm})$ and formation of crystalline oxide $(20 \sim 50 \mathrm{~nm})$ at the oxide/matrix interface after isothermal annealing for 15 hours at $873 \mathrm{~K}$; and (4) accelerated growth of $\mathrm{YAlO}_{3}$ crystalline oxide $(\sim 500 \mathrm{~nm})$ after annealing for 30 hours at $873 \mathrm{~K}$. Such an overall oxidation step observed in $\mathrm{Al}_{87} \mathrm{Ni}_{3} \mathrm{Y}_{10}$ metallic glass suggests that the presence of aluminum and yttrium (instead of only aluminum) in the oxide layer significantly enhances the thermal stability of the amorphous structure in the oxide phase. The amorphous oxide can become thermally stable, when the nucleation of the crystalline oxide is suppressed. Since the oxidation proceeds by inward diffusion of oxygen ions, the nucleation of the crystalline oxide also can occur when inward diffusion of oxygen ions toward the oxide/ matrix interface is enough, i.e. inward diffusion of oxygen ions becomes the rate-controlling step. The extensive growth of amorphous oxide layer can be explained from the point of view of the amorphous structure in the oxide phase. Since the structure of aluminum-yttrium oxide is dense due to the large difference in ionic radius between aluminum and yttrium ions, the diffusion of oxygen ion through the amorphous oxide layer is limited thus stabilizing the amorphous structure of the oxide phase.

The result mentioned above has been obtained when the $\mathrm{Al}_{87} \mathrm{Ni}_{3} \mathrm{Y}_{10}$ alloy with an amorphous structure is exposed at $873 \mathrm{~K}$. Here, it is highly required that the oxidation behavior of the counterpart crystalline $\mathrm{Al}_{87} \mathrm{Ni}_{3} \mathrm{Y}_{10}$ alloy should be investigated under the same condition. Therefore, the aim of the present study is to investigate the oxidation behavior of the crystallized $\mathrm{Al}_{87} \mathrm{Ni}_{3} \mathrm{Y}_{10}$ alloy when heated at $873 \mathrm{~K}$.

\section{MATERIALS AND METHODS}

Alloy ingots with a nominal composition of $\mathrm{Al}_{87} \mathrm{Ni}_{3} \mathrm{Y}_{10}$ were prepared by arc-melting high-purity (>99.9\%) metals in a watercooled copper crucible under a protective argon atmosphere. To prepare the crystallized sample, the alloy was solidified with a slower cooling rate than in the case of melt-spinning method. Therefore, the alloy was re-melted and then solidified into $2 \mathrm{~mm}$ diameter cylinder-shape samples by using a suction casting method. The crystalline structure of the suction-cast samples was confirmed by X-ray diffractometry (XRD, D8 Discover; Bruker AXS, Billerica, MA, USA). Oxidation experiments were performed using a thermo-gravimetric analyzer (TGA 4000; Perkin Elmer, Foster City, CA, USA) with a heating rate of $40 \mathrm{~K} / \mathrm{min}$ in high purity dry air (>99.99\%) at constant flow rate $\left(20 \mathrm{~cm}^{3} /\right.$ min). Thin cross-sectioned samples were prepared using a focused ion beam equipment (FIB, Helios Nano Lab 600; FEI, Hillsboro, OR, USA) to analyze the oxidation behavior using a transmission electron microscope (TEM, Tecnai G2 F20; FEI) linked with an energy dispersive spectrometer (EDS, PV9761 $\mathrm{Si}(\mathrm{Li})$ detector; EDAX, Mahwah, NJ, USA).

\section{RESULTS AND DISCUSSION}

Fig. 1 shows cross-sectional images obtained from the suction-cast $\mathrm{Al}_{87} \mathrm{Ni}_{3} \mathrm{Y}_{10}$ sample continuously heated up to 873 $\mathrm{K}$. The high-resolution electron microscope (HREM) image shown in Fig. 1A shows that the oxide layer still retained an amorphous structure (epoxy coating layer for FIB processing of the TEM sample is also marked in Fig. 1A). Considering that the thickness of the native amorphous oxide layer is $\sim 4 \mathrm{~nm}$ (Reichel et al., 2008), the HREM image in Fig. 1A indicates that the thickness of the amorphous oxide layer increased up to $\sim 10 \mathrm{~nm}$ during heating. The high-angle annular dark-field scanning TEM (HAADF-STEM) image in Fig. 1B shows crystallization products embedded in the a-Al matrix. The identification of the crystalline phases is reported in the previous study (Kim et al., 2013). Due to low
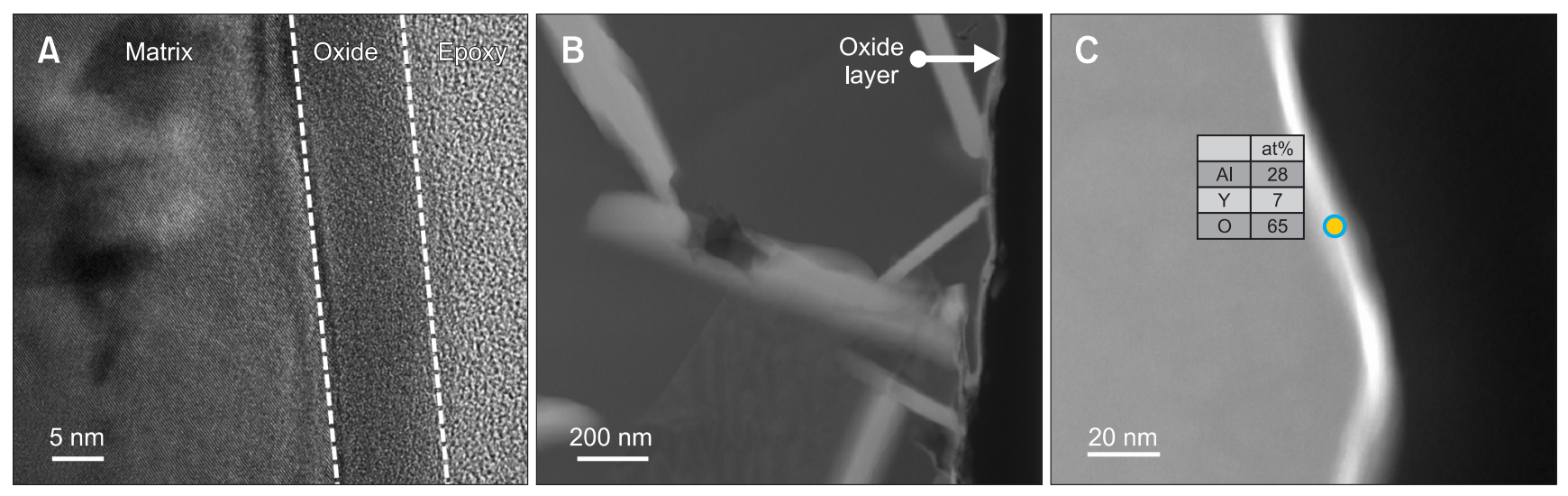

Fig. 1. Transmission electron microscope (TEM) images obtained from suction-cast $\mathrm{Al}_{87} \mathrm{Ni}_{3} \mathrm{Y}_{10}$ continuously heated up to $873 \mathrm{~K}$. (A) High-resolution electron microscope image. (B) Lower magnification high-angle annular dark-field scanning TEM (HAADF-STEM) image. (C) Higher magnification HAADF-STEM image and energy dispersive spectrometer result. 
magnification, the oxide layer could not be clearly discerned in Fig. 1B. In the high magnification HAADF-STEM image (Fig. 1C), the oxide layer can be observed. From the EDS analysis (Fig. 1C), the composition of the oxide layer was determined as $28 \% \mathrm{Al}-7 \% \mathrm{Y}-65 \% \mathrm{O}$, indicating that a small amount of yttrium is present in the oxide phase.

Fig. 2 shows cross-sectional images obtained from the suction-cast $\mathrm{Al}_{87} \mathrm{Ni}_{3} \mathrm{Y}_{10}$ sample isothermally annealed at 873 $\mathrm{K}$ for 30 hours. As can be seen in the in the HAADF-STEM image (Fig. 2A, the thickness of the oxide layer increased up to $\sim 250 \mathrm{~nm}$, and the oxide layer now consists of two different phases with darker and lighter contrast. The darker contrast outer layer with a thickness of $\sim 20 \mathrm{~nm}$ was confirmed to have an amorphous structure, while the lighter contrast inner layer with a thickness of $\sim 230 \mathrm{~nm}$ is a crystalline oxide. HREM images in Fig. $2 \mathrm{~B}$ and $\mathrm{C}$ are taken from the area ' $\mathrm{a}$ ' and ' $\mathrm{b}$ ' marked in Fig. 2A, respectively. The HREM image in Fig. 2B shows a faceted-type interface between the crystalline oxide layer and the matrix. The strong intensity diffraction spots in the selected area diffraction pattern was indexed as a [201] zone of the hexagonal structure of $\mathrm{YAlO}_{3}$, as in the previous study. On the other hand, the low intensity diffraction spots could not be indexed unanimously with the Y-Al-O crystalline structure reported so far. In contrast a faceted-type interface between the crystalline oxide layer and the matrix, a wavy-type interface between the crystalline and amorphous oxide layers was observed, as can be seen in Fig. 2C. The result indicates that the amorphous structure of the oxide phase still remains even after holding at $873 \mathrm{~K}$ for 30 hours, although a large fraction of the crystalline oxide formed at the interface between the oxide layer and the matrix. The EDS results from the HAADF-STEM image (Fig. 2A) indicate that the amorphous and crystalline oxide layers have different compositions, i.e. 19\%Al-8\%Y-73\%O and 25\%Al-24\%Y-
$51 \% \mathrm{O}$, respectively. Here, it can be noticed that the amount of yttrium in the crystalline oxide layer is almost same as that of aluminum. The EDS results Figs. 1 and 2 indicates that the amount of yttrium and oxygen in the amorphous structure of the oxide phase increased, while that of aluminum decreased with isothermal treatment. Such a composition change reflects that aluminum-yttrium oxide has a relatively high amorphous phase forming tendency over a wide composition range.

The present observation indicates that the oxidation behavior in the crystallized $\mathrm{Al}_{87} \mathrm{Ni}_{3} \mathrm{Y}_{10}$ alloy occurs in the same way as in the amorphous $\mathrm{Al}_{87} \mathrm{Ni}_{3} \mathrm{Y}_{10}$ alloy. Therefore, as in the case of the amorphous $\mathrm{Al}_{87} \mathrm{Ni}_{3} \mathrm{Y}_{10}$ alloy, the simultaneous presence of aluminum and yttrium in the oxide layer significantly enhances the thermal stability of the amorphous structure in the oxide phase which grows from the crystallized matrix. Since the structure of aluminum-yttrium oxide is dense due to the large difference in ionic radius between aluminum and yttrium ions, the diffusion of oxygen ion through the amorphous oxide layer is limited, thus stabilizing the amorphous structure of the oxide phase.

\section{SUMIMARY}

In the present study, the oxidation behavior of the crystallized $\mathrm{Al}_{87} \mathrm{Ni}_{3} \mathrm{Y}_{10}$ alloy has been investigated with an aim to compare with that of the amorphous $\mathrm{Al}_{87} \mathrm{Ni}_{3} \mathrm{Y}_{10}$ alloy. When the crystallized alloy is oxidized at $873 \mathrm{~K}$, the overall oxidation process can be described as follows: (1) growth of an amorphous aluminum-yttrium oxide layer $(\sim 10 \mathrm{~nm})$ after heating up to $873 \mathrm{~K}$; and (2) formation of $\mathrm{YAlO}_{3}$ crystalline oxide $(220 \mathrm{~nm})$ after annealing for 30 hours at $873 \mathrm{~K}$. Such an overall oxidation step indicates that the oxidation behavior in the crystallized $\mathrm{Al}_{87} \mathrm{Ni}_{3} \mathrm{Y}_{10}$ alloy occurs in the same way
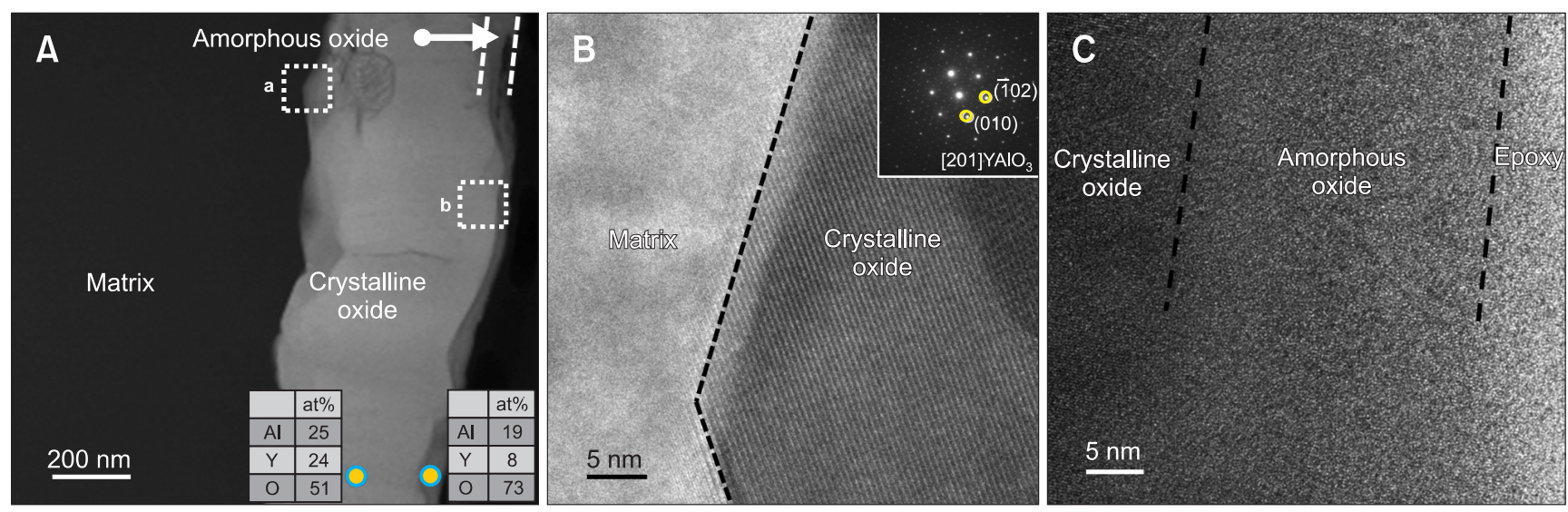

Fig. 2. Transmission electron microscope (TEM) images obtained from suction-cast $\mathrm{Al}_{87} \mathrm{Ni}_{3} \mathrm{Y}_{10}$ isothermally heated at $873 \mathrm{~K}$ for 30 hours. (A) High-angle annular dark-field scanning TEM image and energy dispersive spectrometer result. (B, C) High-resolution electron microscope images obtained from the region marked ' $a$ ' and ' $b$ ' in (A). 
as in the amorphous $\mathrm{Al}_{87} \mathrm{Ni}_{3} \mathrm{Y}_{10}$ alloy. As in the amorphous $\mathrm{Al}_{87} \mathrm{Ni}_{3} \mathrm{Y}_{10}$ alloy, the simultaneous presence of aluminum and yttrium in the oxide layer significantly enhances the thermal stability of the amorphous structure in the oxide phase.
Due to the dense structure of aluminum-yttrium oxide, the diffusion of oxygen ion through the amorphous oxide layer is limited, thus stabilizing the amorphous structure of the oxide phase.

\section{REFERENCES}

Carmo M, Sekol R C, Ding S, Kumar G, Schroers J, and Taylor A D (2011) Bulk metallic glass nanowire architecture for electrochemical applications. ACS Nano 5, 2979-2983.

Han J, Song G, Park E, Lee S, Park J, Seo Y, Lee N, Lee W, and Kim K (2011) Effect of microstructure modulation on mechanical properties of TiFe-Sn ultrafine eutectic composites. Met. Mater. Int. 17, 873-877.

Kim K C, Lim K R, Lee E S, Kim W T, Gebert A, Eckert J, and Kim D H (2013) Thermal stability of amorphous oxide in Al87Ni3Y10 metallic glass. Corros. Sci. 77, 1-5.

Kim S J, Kim S Y, Park J M, Heo J N, Lee J H, Lee S M, Kim D H, Kim W T, Lim K R, and Kim D (2012) Exploiting metallic glasses for 19.6\% efficient back contact solar cell. Appl. Phys. Lett. 101, $064106-$ 064106-4.

Lim K R, Kim W T, Lee E S, Jee S S, Kim S Y, Kim D H, Gebert A, and Eckert J (2012) Oxidation resistance of the supercooled liquid in Cu50Zr50 and Cu46Zr46Al8 metallic glasses. J. Mater. Res. 27,
1178-1186.

Lim K R, Park J M, Jee S S, Kim S Y, Kim S J, Lee E S, Kim W T, Gebert A, Eckert J, and Kim D H (2013a) Effect of thermal stability of the amorphous substrate on the amorphous oxide growth on $\mathrm{Zr}-\mathrm{Al}-(\mathrm{Cu}$, Ni) metallic glass surfaces. Corros. Sci. 73, 1-6.

Lim K R, Park J M, Kim S J, Lee E S, Kim W T, Gebert A, Eckert J, and Kim D H (2013b) Enhancement of oxidation resistance of the supercooled liquid in Cu-Zr-based metallic glass by forming an amorphous oxide layer with high thermal stability. Corros. Sci. 66, 1-4.

Nakayama K S, Yokoyama Y, Wada T, Chen N, and Inoue A (2012) Formation of metallic glass nanowires by gas atomization. Nano Lett. 12, 2404-2407.

Reichel F, Jeurgens L, Richter G, and Mittemeijer E (2008) Amorphous versus crystalline state for ultrathin AIO overgrowths on Al substrates. J. Appl. Phys. 103, 093515. 